Thorax (1952), 7, 66.

\title{
VENTILATORY FUNCTION IN BRONCHIAL ASTHMA
}

\author{
BY \\ W. A. BRISCOE AND G. A. McLEMORE, Jr. \\ From the Postgraduate Medical School of London
}

(RECEIVED FOR PUBLICATION SEPTEMBER 30, 1951)

Ventilation of the lungs is seriously impaired in the asthmatic paroxysm. There is obvious interference with the free exchange of tidal air, but, with considerable effort, the total minute ventilation is often maintained at normal levels. Thus the ventilatory defect cannot be measured in terms of a reduction in minute ventilation or tidal air. Birath (1944) and many other workers have assessed the ventilatory defect in terms of an increase in "physiological dead space" in the lung. This defect, however, may more properly be regarded as due to uneven ventilation of different parts of the lung. A spirometric method recently developed permits the approximate assessment of the degree of uneven ventilation of the lungs in terms of the volume and ventilation of the poorly ventilated space, or spaces, hereafter referred to as P.V.S. (Briscoe, 1952). It is the purpose of this paper to describe some studies on asthmatic subjects using this method.

\section{Clinical Material and Methods}

Ten patients with ages ranging from 9 to 55 years were studied, each in at least two different phases of their asthma. All cases were associated with bronchitis rather than with allergic factors of a non-infective nature. The therapeutic response to subcutaneous adrenaline was poor, a fact in keeping with clinical experience in this type of asthma. In several cases the asthma was sufficiently severe to necessitate hospital admission The older patients were emphysematous. The clinical state was carefully re-checked at the time of investigation. Their exercise tolerance was observed at each study by noting whether they were dyspnoeic at bed-rest, walking slowly, walking rapidly, or running. In four cases the response to subcutaneous injection of $1 \mathrm{ml}$. of a 1/1,000 solution of adrenaline hydrochloride was studied. A summary of each case history is given in the appendix.

A closed circuit Knipping spirometer system was used to measure the functional residual air (F.R.A.) and total lung volume (T.L.V.) by the method of McMichael (1939) with helium as the indicator gas using a katharometer for gas analysis. The oxygen consumption, the mean of three vital capacities (Gilson and Hugh-Jones, 1949), and the maximum breathing capacity (M.B.C.) were determined in a preliminary study. Our lung volume spirometer was used for the estimation of M.B.C. (with the circulating pump switched off to prevent excessive loss of $\mathrm{CO}_{2}$ from the patient and a high oxygen mixture to prevent anoxia), normal values with this instrument (mean 84 litres per minute in 20 normal subjects of both sexes) being lower than those achieved with specially constructed apparatus. The spirometer was prepared for the mixing study by the addition to its dead space of $500 \mathrm{ml}$. of helium, $575 \mathrm{ml}$. of room air, and $125 \mathrm{ml}$. of oxygen, after which the total volume of the circuit was $4,000 \mathrm{ml}$. with a helium concentration of $12.5 \%$ and an oxygen concentration of $21 \%$. The pump circulated this 
gas mixture at the rate of 40 litres per minute. The patient rebreathed from the circuit for eight to 12 minutes during which time oxygen was added to the circuit at a rate previously determined as necessary to balance his oxygen consumption. The falling concentration of helium in the spirometer was recorded on the drum with the respiratory tracing by a signal pen operated by an assistant watching the katharometer. The rate at which inhaled helium is diluted into the lung is studied by the construction of a mixing curve (Briscoe, 1952). A function of the falling helium concentration was plotted logarithmically against time (Fig. 1). This function $\left(x_{n}-x_{\infty}\right)$, plotted on the logarithmic scale of ordinates, is the amount by which the helium concentration at any moment $\left(x_{n}\right)$ exceeds the final constant concentration $\left(\mathrm{x}_{\infty}\right)$ reached in the spirometer.

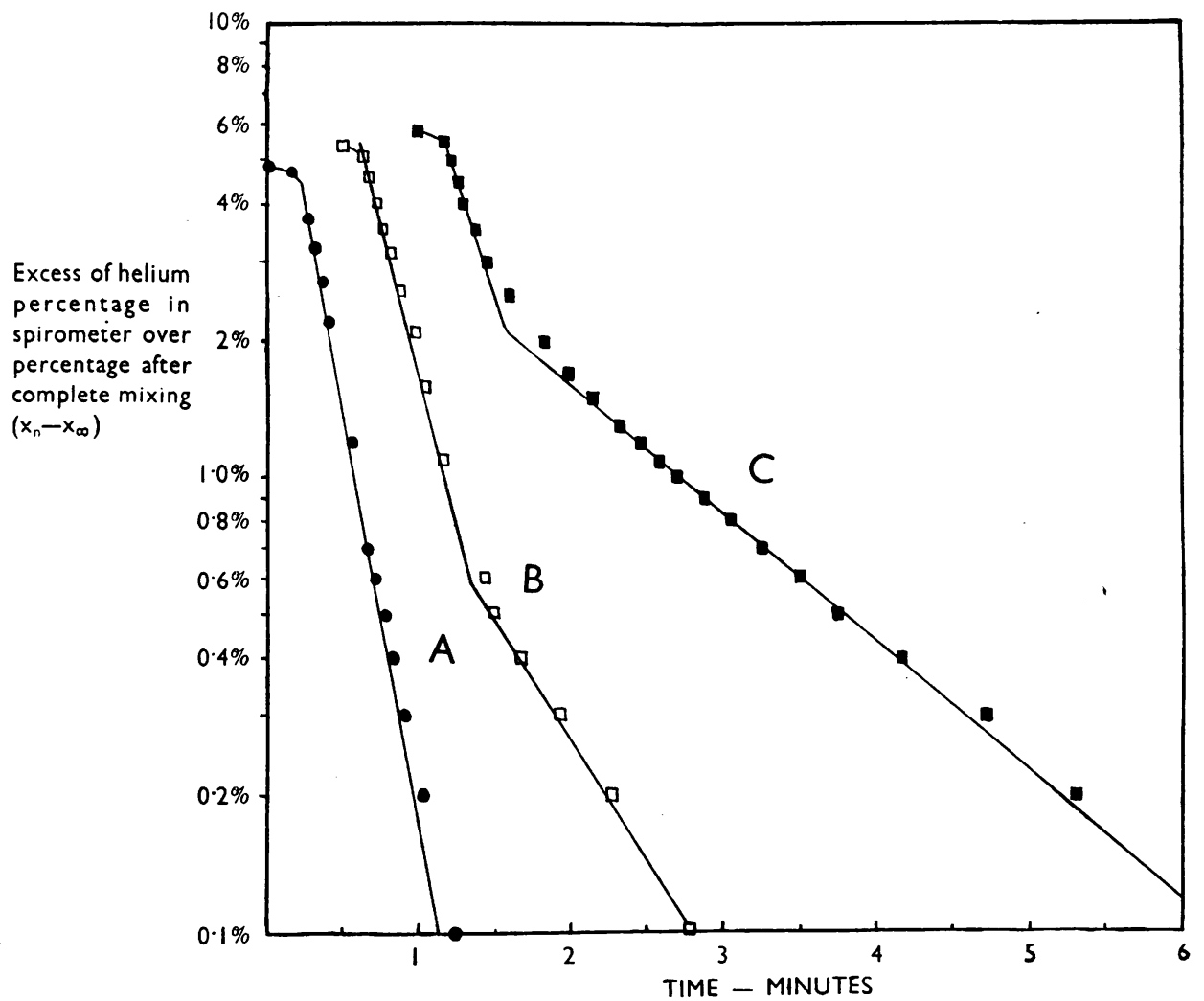

Fig. 1.-Mixing curves of Case 2 in asthmatic spasm (C); same case after recovery (B); and of a rormal subject (A).

The $90 \%$ mixing ratio (Bates and Christie, 1950) compares the observed behaviour of the patient's lung with the predicted behaviour of an ideal lung with the same tidal air. It is the ratio of the predicted number of breaths to reach the point of $90 \%$ mixing to the observed number of breaths necessary to attain $90 \%$ mixing in the patient. It assesses the ventilation of the lung as a whole without implications as to whether the ventilatory defect is due to uneven ventilation or to a large dead space.

In normal subjects the concentration of helium falls rapidly and almost exponentially towards its final constant concentration. The points plotted on the mixing curve 
approximate to a steeply falling straight line (Fig. 1, curve A). When the lung is unevenly ventilated the mixing curve when plotted by the method of Briscoe (1952) shows an initial rapid fall of helium concentration in the spirometer, followed by a later slow fall. From an analysis of such curves an estimate of the volume of P.V.S. can be made by observing the point of inflection of the curve, which is higher on the graph when the P.V.S. is large. The ventilation of the P.V.S. can be approximately assessed by the slope of the later part of the curve : the less steep this line, the worse the ventilation of the P.V.S. If $T=$ tidal air of the whole lung, $C=F . R . A ., t_{2}=$ tidal air of poorly ventilated space, $c_{2}=$ volume of poorly ventilated space, the ratio $\left(t_{2} / c_{2}\right) /(T / C)$ gives a numerical assessment of the ventilatory defect of this P.V.S. by comparing its ventilation per unit volume $\left(t_{2} / c_{2}\right)$ with that of the whole lung $(T / C)$.

Most of the results presented are the means of two consecutive studies.

\section{RESULTS}

The principal findings are shown graphically in Fig. 2, the patients being arranged in order of decreasing exercise tolerance and the data on each patient in chronological order.



FIG. 2.-Results of serial studies in $\mathbf{1 0}$ asthmatics. Normal values for poorly ventilated space and subdivisions of lung volume, maximum breathing capacity, $90 \%$ mixing ratio, ventilation of poorly ventilated space $\left(t_{2} / c_{2}\right) /(T / C)$, and exercise tolerance are indicated in the right-hand margin for comparison with the findings in the asthmatic subjects. (The maximum breathing capacity was not measured at the first study on subject 5 .)

None of the subjects having bronchospasm gave normal values for any of our measurements. These results for lung volume subdivisions in "asthma " agree with those of previous workers (Hurtado and Kaltreider, 1934): the vital capacity is reduced and the residual air correspondingly increased to a value between $61 \%$ and $80 \%$ of the T.L.V., the average being $64.5 \%$. In normal subjects the residual air seldom exceeds $35 \%$ and averages $29 \%$ of the T.L.V. with our apparatus. The F.R.A. was also increased to a value between $72 \%$ and $85 \%$ of the T.L.V. (normal average $54 \%$ ). 
The M.B.C. was consistently reduced to 10-35 litres per minute. With our apparatus the normal value should not fall below about 60 litres in women and 70 litres in men.

Mixing studies were abnormal in every case with asthmatic spasm. The attainment of the final constant concentration in the spirometer is delayed. The concentration does not fall rapidly towards its final value as is the case in normal subjects (Fig. 1, curve A). Though the logarithmically plotted data show that there is an initial rapid fall in concentration, due to the rapid mixing of helium into the well-ventilated parts of the lung, this is soon superseded by a slower rate of fall due to the slower mixing of helium into the P.V.S. (Fig. 1, curve C). This is similar to the type of mixing curve seen in emphysema.

The volume of P.V.S. in the lung varied between 900 and 3,400 ml., whereas normal subjects seldom show any detectable P.V.S. (Briscoe, 1952). The $90 \% \mathrm{mix}-$ ing ratio was reduced to between 0.08 and 0.18 , the range of normal values with our apparatus lying between 0.38 and 0.60 . The estimated ventilation of P.V.S. $\left(\mathrm{t}_{2} / \mathrm{c}_{2}\right) /(\mathrm{T} / \mathrm{C})$ gave values close to those of $90 \%$ mixing ratio. When the volume of the P.V.S. is assessed at more than a litre the ventilation of this space apparently determines, to a large extent, that of the lung as a whole $(90 \%$ mixing ratio). In those subjects who improved sufficiently to reduce the volume of P.V.S. to $400 \mathrm{ml}$. or less, the $90 \%$ mixing ratio underwent a considerable parallel improvement. The ventilation of the small remaining P.V.S., however, did not necessarily show marked improvement.

These mixing studies confirm that the defective ventilation in asthma is not of the type which would be caused by an increase in dead space, nor is it of the type due to a large volume of functional residual air less adequately ventilated by the same tidal air. Both these types of ventilatory defect give mixing curves with the points lying on a gradually falling straight line (Briscoe, 1952). The shape of the mixing curves show that, as in emphysema, the ventilatory defect is due to grossly uneven ventilation of different parts of the lungs. The results suggest that the unevenness of ventilation in the cases of asthma here reported is of such a degree that a P.V.S. of more than a litre receives less than one-fourth its due share of ventilation.

\section{Follow-UP StUdies}

All patients were studied again after an interval of weeks or months when, in most cases, there had been some considerable change in disability. Cases 1 to 6 had improved, Cases 7 and 8 were unchanged, and Cases 9 and 10 had deteriorated (Fig. 2).

The vital capacity increased in the six patients who improved and also in the two further cases which showed no change by our rough clinical assessment. In these eight cases there was a corresponding decrease in the residual air expressed as a percentage of T.L.V., the greatest decrease being from $64 \%$ to $28 \%$ of the T.L.V. in Case 1 and the smallest decrease being from $71 \%$ to $66 \%$ of the T.L.V. in Case 8 . In Case 5, a growing boy, though the increase in vital capacity was associated with a small increase in the absolute value of the residual air, there was a small decrease in the volume of residual air expressed as a percentage of T.L.V. In the two cases where the exercise tolerance deteriorated between studies, the vital capacity decreased and the residual air percentage increased. 
The M.B.C. of any one subject was generally greatest at the study which showed the largest vital capacity and smallest residual air (Fig. 2). The only exception was in Case 6 when, at the second study, a small decrease in M.B.C. coincided with a small increase in vital capacity and reduction in residual air.

In Cases 1 and 2 the mixing curves reverted practically to normal, as did the exercise tolerance (Fig. 1, curves C and B). In six cases (Nos. 3 to 8) there was a decided change towards normal in that the inflection in the mixing curve was lower, indicating a smaller P.V.S. In Cases 9 and 10 the inflection was higher, indicating a larger P.V.S. at the second study. Thus the changes in the estimated P.V.S. always followed inversely changes in vital capacity in any one subject. The greatest decrease in this volume was from $1,900 \mathrm{ml}$. to $400 \mathrm{ml}$. in Case 1. The average decrease in these eight cases was $650 \mathrm{ml}$.

The $90 \%$ mixing ratio showed an improvement in seven of the eight cases with an increase in vital capacity and no significant change in the remaining case. There was a decrease in this index in the two cases which had a smaller vital capacity at the second study. Changes in the estimated ventilation of the P.V.S. were always in the same direction as changes in the $90 \%$ mixing ratio.

\section{EFFects OF Adrenaline}

The results are shown in Fig. 3. All our asthmatic subjects were attending the hospital because they obtained little relief from injections of adrenaline or because of the severity of their paroxysms.

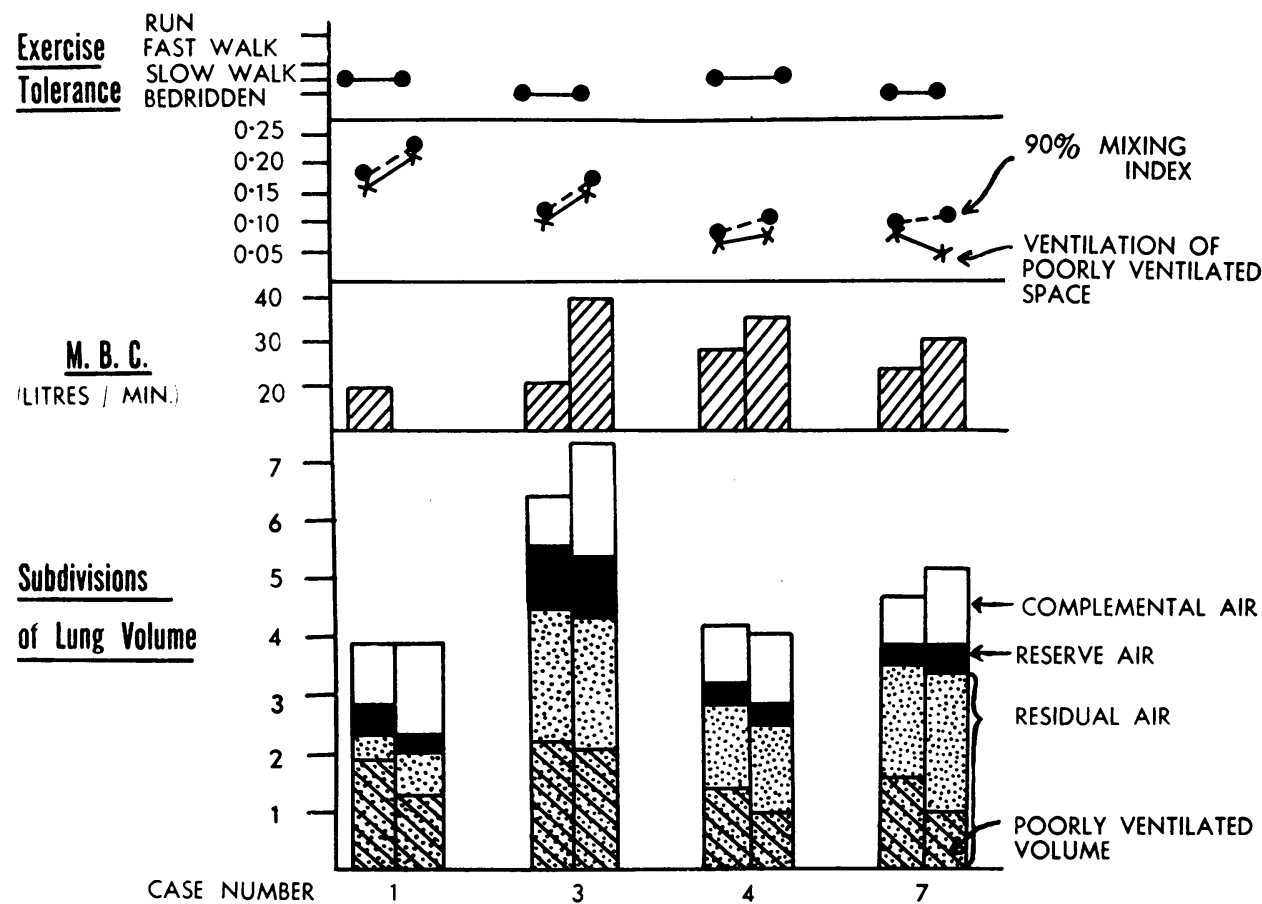

FIG. 3.-The effects of adrenaline on subdivisions of lung volume, maximum breathing capacity, and mixing indices in four asthmatic subjects. 
Although subcutaneous injection of $1 \mathrm{ml}$. of adrenaline hydrochloride $(1 / 1,000)$ was followed by some subjective relief, there was little material improvement in exercise tolerance. In no case was there typical post-asthmatic expectoration after adrenaline. The vital capacity in each case increased, and the residual air expressed as a percentage of T.L.V. showed a corresponding decrease, by an average of $9 \%$ (cf. Hurtado and Kaltreider, 1934). The M.B.C. increased in every case after administering adrenaline, the greatest change being from 21 to 38 litres per minute. The minute ventilation increased in three out of four cases. The shape of the mixing curve, while showing some slight improvement, never returned to normal in any case after the injection of adrenaline. The estimated volume of P.V.S. decreased in every case, the average reduction being $400 \mathrm{ml}$. The $90 \%$ mixing ratio increased slightly in all, the average increase being 0.03 .

\section{Discussion}

Many writers; such as Birath (1944) and Bateman (1946), have interpreted the ventilatory defect of asthma in terms of an increase in physiological dead space. By most methods it is difficult to distinguish this type of defect from the derangement of ventilation caused by uneven ventilation of the lungs. The method of serial analysis of alveolar air was used by Roelsen $(1938,1939)$ to show that asthmatic lungs are grossly unevenly ventilated, and a similar technique, using physical methods of analysis, has more recently been used by Fowler (1949). It appears that the distinction between the effects of uneven ventilation and those of a large dead space cannot be drawn with certainty from a mixing curve unless several points on the mixing curve are plotted (Briscoe, Becklake, and Rose, 1951) preferably on a logarithmic scale (Briscoe, 1952). The present study shows that the mixing curve in asthmatics has the initial rapid equilibration and the subsequent slowing of this process which characterize grossly uneven ventilation of different parts of the lung. This finding is not unexpected. If the ventilatory defect of asthma were due to an increase in dead space it should be possible to compensate for it by an increase in tidal air. Increase in the anatomical dead space up to about four times the normal would be needed to account for the similar ventilatory defect of emphysema (Bateman, 1946). If an increase in dead space were the mechanism of the mixing defect it should be possible to find some morbid anatomical evidence of so large a change in the volume of the air passages.

There is, however, morbid anatomical support for uneven ventilation in the asthmatic lung: narrowing of the bronchial lumen may vary considerably in different parts of the same lung. Necropsy studies (Huber and Koessler, 1922) suggest that a major cause of the partial bronchial occlusion found in asthma is the adherence of viscid secretion to the bronchial walls rather than spasm of bronchial muscle. The poor response to adrenaline in the present selected group of asthmatic bronchitics suggests that in them viscid bronchial secretion rather than spasm of bronchial muscle is of major importance.

Several different assessments of ventilatory function were used in this study, and all tended to change in a corresponding manner. Fig. 4 shows how the diminution in M.B.C. is related to the increase in residual air expressed as a percentage of T.L.V. There is a similar correlation between increasing estimates of P.V.S. and increases in residual air expressed as a percentage of T.L.V., as shown in Fig. 5. 


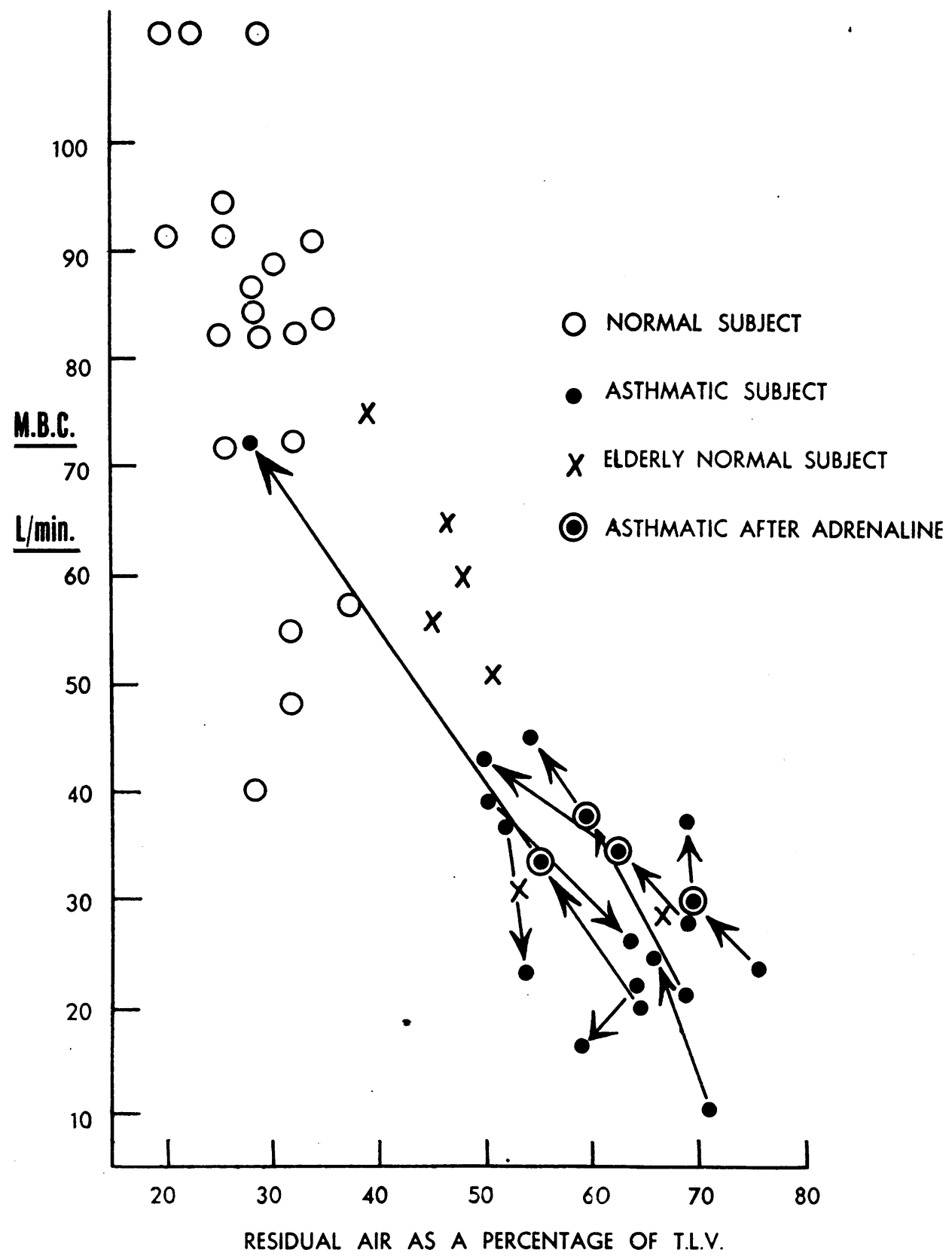

FIG. 4.-The relation between residual air and maximum breathing capacity in asthmatic subjects before and after adrenaline, and in normal and elderly normal subjects. The data for the normal groups are taken from Briscoe (1952). Each arrow shows the sequence of studies in one asthmatic subject studied on several occasions. 


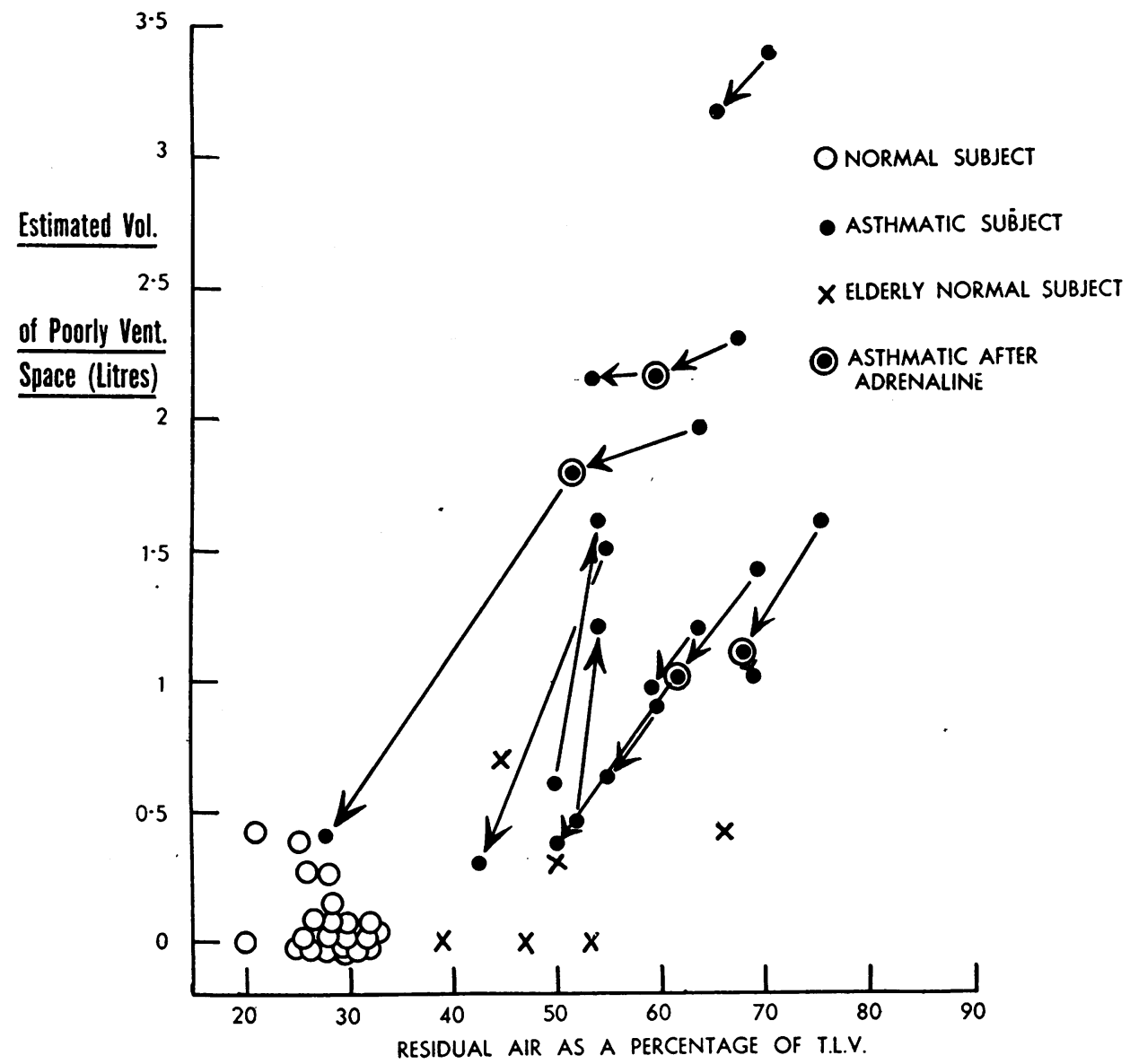

Fig. 5.-The relation between residual air and volume of poorly ventilated space in asthmatic subjects, before and after adrenaline, and in normal and elderly normal subjects.

No relationship was found between the duration of the asthma and the increase in the residual air, in agreement with the findings of Hurtado, Kaltreider, Fray, Brooks, and McCann (1934). These correlations suggest that, if it is desired merely to measure the improvement or deterioration of ventilatory function in a single asthmatic subject, it is not necessary to use batteries of tests. Any one test will usually show the trend in all the others. The simplest test for such repeated clinical measurements is the vital capacity, changes in which appear to be closely related to changes in the clinical state of any one patient. In different patients, however, the degree of disability is not necessarily closely related to the magnitude of their vital capacities. This measurement by itself does little to confirm the diagnosis of asthma or the degree of disability in a patient who is studied on one occasion only. 


\section{SUMMARY}

Ten infective asthmatic subjects were studied in two phases of their disease. Four of these subjects were also re-studied immediately after an injection of adrenaline. Measurements were made of vital capacity, residual air, total lung volume, maximum breathing capacity, $90 \%$ mixing index, and the volume and ventilation of poorly ventilated space or spaces (P.V.S.).

All subjects with asthmatic spasm showed definite abnormality by all the measurements made. Vital capacity averaged only 1.61 litres and residual air averaged $64 \%$ of total lung volume. Maximum breathing capacity averaged only 23 litres per minute. The $90 \%$ mixing index averaged 0.14 and the volume of P.V.S. averaged $1,695 \mathrm{ml}$., with a ventilation per unit volume only 0.129 of that of the whole lung.

In all cases the vital capacity was greatest at the study showing the best exercise tolerance, and in all cases the P.V.S. assessed from the mixing curve was then smallest. In almost every case the $90 \%$ mixing index, the maximum breathing capacity, and the ventilation of the P.V.S. were greatest at the study showing the best exercise tolerance.

Though adrenaline had little effect on exercise tolerance, it improved all these indices of ventilation and gave some subjective relief to the patients.

Where a single measurement is required as an index of change in ventilatory function at serial studies in any one patient, the vital capacity remains the simplest and most reliable test.

\section{L I N I C A L A P P E N D I X}

The following summaries are of those cases which form the basis of this study.

Case 1.-A woman, aged 28 , had no dyspnoea till she developed a cold six weeks before study, followed by wheezing and dyspnoea which forced her to bed. She was admitted on September 30,1950 , as a case of status asthmaticus, orthopnoeic and cyanosed, with numerous high-pitched rhonchi and a normal chest radiograph. She showed no response to ephedrine, but some subjective improvement after subcutaneous adrenaline and intravenous aminophylline.

At the time of the first study (October 13, 1950) she had improved sufficiently to walk about the ward slowly. She was re-studied after subcutaneous adrenaline, which produced some subjective relief, some improvement in the various indices of lung ventilation, but no improvement in exercise tolerance. There was no detectable change in rhonchi, but some diminution in expiratory wheezes.

At the follow-up study (December 8, 1950) she had been free from all dyspnoea for six weeks, could run, appeared perfectly well, and had no sputum. No rhonchi were audible. Most of the various indices of ventilation had returned to normal (Fig. 2).

Case 2.-A woman, aged 23 years, one year before study had developed bronchitis for the first time; this persisted. One month after this attack she awakened in the night, short of breath and wheezing. An adrenaline spray helped only slightly. Spasmodic attacks of wheezing persisted throughout the following summer. No allergic factor was discovered. When first studied (February 1, 1950) she had improved somewhat and showed only a few rhonchi. She was unable to walk rapidly without dyspnoea. A chest radiograph was normal. After this study she married and completely lost all breathlessness, cough, and sputum. At a follow-up study (April 1, 1951) she was pregnant. There were no adventitious sounds in her chest and she could walk rapidly upstairs. 
Case 3.-A man, aged 34 years, one month before the first study developed asthmatic dyspnoea for the first time following a severe cold, with cough and expectoration. The paroxysms of wheezing were not relieved by injections of adrenaline. He was admitted on October 22, 1950, because of status asthmaticus. Mixing studies were made next day, when he was still orthopnoeic, with copious, tenacious, greyish-white, mucoid sputum. There were generalized rhonchi over the chest, high-pitched and squeaky. A chest radiograph showed increased bronchial markings. An injection of $1 \mathrm{ml}$. adrenaline hydrochloride $1 / 1,000$ gave some subjective relief, but the physical signs were unchanged and his exercise tolerance failed to improve (Fig. 3). At the second study (November 10,1950 ) he had improved, could walk at a moderate pace, but could not run. There were fewer rhonchi than before.

Case 4.-A woman, aged 55 years, had infrequent colds which were always followed by bronchitis. She had left-sided pneumonia in 1933. One year before study she had had a severe cold, bronchitis, and, for the first time, asthmatic wheezing. Paroxysms of wheezing, dyspnoea, and productive cough were helped by ephedrine, but its effectiveness diminished with time. Wheezing episodes cleared during the summer months, but recurred six weeks before study, when another chest cold precipitated the same symptoms, which persisted. At the first study she exhibited wheezing, anxiety, and dyspnoea which prevented her walking more than a short distance slowly. Many high-pitched expiratory rhonchi and scattered coarse crepitations were audible. A chest radiograph showed a calcified focus in the left apex, but the lung fields were otherwise normal. Adrenaline hydrochloride, $1 / 1,000 \mathrm{ml}$., in $1 \mathrm{ml}$. doses, had no appreciable effect on exercise tolerance or the coarse crepitations, but there were fewer expiratory rhonchi. The arterial oxygen saturation was 79\%. At the follow-up study (March 8, 1951), after three weeks' treatment with expectorants, sedation, and ephedrine, she was considerably improved, but had a cough worse in the mornings and productive of two teaspoonfuls of greyish sputum per day. A few coarse crepitations and occasional high-pitched musical rhonchi were heard. The arterial oxygen saturation was now $92 \%$. She could walk a mile at a moderate pace.

Case 5.-A boy, aged 9 years, had had recurrent bronchial asthma since the age of 18 months. He had pertussis when aged 7 years and pneumonia then and on a subsequent occasion. Skin tests showed sensitivity to grass. His asthma was worse in winter ; "colds" led to wheezing, with cough productive of very viscid sputum. Ephedrine and adrenaline helped but never completely relieved the asthmatic wheezing. Hot drinks were of greatest benefit. There was no cyanosis or clubbing. The child was small for his age. Scattered wheezes and rhonchi were heard at the time of the first study, but the boy was supposedly free of an acute asthmatic attack, though he walked with difficulty. At the second study (April 24, 1951) he was considerably improved and had had few asthmatic attacks. Weight had increased from 53 to $61 \mathrm{lb}$. He had had no sputum, wheezing, or cough in the previous five weeks. The chest was clear except for an occasional rhonchus on the left. A chest radiograph was normal, except for some increased translucency. He could now run short distances.

Case 6.- $\AA$ ' woman, aged 52 years, had had chronic cough for 10 years, worse in winter, which was complicated by right-sided pneumonia in 1944, 1946, and 1948. Dyspnoea in fog had been troublesome for about five years. Partial gastrectomy (September 4,1950 ) for chronic gastric ulcer was successful, but she developed an acute respiratory infection at home shortly afterwards, with cough and sputum and persistent wheezing. Ephedrine by mouth and adrenaline injections at home were of little benefit, and she was admitted on October 16,1950, as a case of bronchitis and asthma. The course of her illness was afebrile, but she had copious purulent sputum. Penicillin, expectorants, and postural drainage diminished the cough and the volume of sputum. The first mixing study was made on October 17, 1950, when she was in respiratory distress at rest. The 
chest was hyperresonant, with many rhonchi. A radiograph showed mottling in both upper lung fields. There were no tubercle bacilli in the sputum. An E.C.G. showed $P$ pulmonale, partial right bundle branch block. There was no cardiac enlargement or signs of cardiac disease. Blood pressure was 140/80. The second study (March 20, 1951) was made when she had improved and could walk one mile slowly. She had a slight residual cough, productive of about $60 \mathrm{ml}$. of mucopurulent sputum daily, and occasional attacks of nocturnal dyspnoea. There was no cyanosis, but some expiratory rhonchi and a few coarse rales. Arterial oxygen saturation was $85 \%$.

Case 7.-A man, aged 31 years, was well until December, 1943, when he had pneumonia, followed by asthmatic wheezing and a persistent cough. Adrenaline relieved the asthma at first, but with diminishing effect, and due to the recurrent asthmatic attacks and "bronchitis" he was discharged from the Army in July, 1944. Since then he had many asthmatic episodes, with dyspnoea, occasional cyanosis, tightness in the chest, and cough productive of white, tenacious, foamy sputum. He had been in prison for the past two years, when these symptoms were more severe and persistent. At the first study on December 7, 1950, he was bedridden and dyspnoeic at rest. Many expiratory rhonchi and slight hyperresonance, more pronounced on the left, were found. The heart was normal. A chest radiograph showed increased bronchial markings and moderately increased translucency of left lung. Bronchoscopy was normal. E.C.G. was normal. Adrenaline hydrochloride, 1/1,000,1 ml., subcutaneously caused no subjective or objective improvement. At the time of the second study one month later he was essentially unchanged and still dyspnoeic at rest.

Case 8.-A man, aged 27 years, had had bronchial asthma in paroxysms since the age of 10 years. He had a chronic productive cough for 15 years, summer and winter. In 1945 pneumonia of undetermined type confined him to bed for two weeks. Walnuts and Brazil nuts produced urticaria and rhinorrhea, but no allergic basis was found for the asthma. For two years before study symptoms became more severe, with increasing cyanosis. Because of signs and symptoms of congestive heart failure, he was admitted on December 6,1950, and treated by digitalization, diuretics, and a low salt diet, with improvement. He was bedridden when first mixing studies were carried out. Blood pressure was $130 / 100$. The retinal veins were much engorged. The heart was much enlarged, but no murmurs were audible. An E.C.G. showed right ventricular strain. There were physical signs of emphysema and kyphosis, with widespread musical rhonchi. The jugular venous pressure was $+4 \mathrm{~cm}$. Haemoglobin was $120 \%$. Cardiac catheterization gave cardiac output, 4 litres per minute ; right ventricular pressure, 47 $\mathrm{mm}$. Hg systolic, $6 \mathrm{~mm}$. diastolic. No atrial septal or other congenital heart defect was found, and failure was attributed to cor pulmonale. Arterial oxygen saturation rose from $72 \%$ to $98 \%$ on breathing oxygen. A second study (January 17, 1951) showed slight improvement, but the patient was still bedridden. There were fewer musical expiratory rhonchi, otherwise the condition was essentially unchanged.

Case 9.-A man, aged 19 years, was admitted because of an asthmatic attack not relieved by adrenaline. His first asthmatic attack was at the age of 10 years, and attacks recurred, associated with colds and bronchitis, three to four times each winter. No allergic factor could be found, and between attacks, especially during the summer, he was free of cough and sputum and could run 200 yards without dyspnoea. There were scattered expiratory rhonchi, and a slight increase in the antero-posterior chest diameter. A chest radiograph showed increased bronchial markings and slightly increased translucency, and an E.C.G., $P$ pulmonale. At the time of the first study (November 12,1949) he had improved sufficiently to walk rapidly. At the time of the second study (March 13, 1951) he was in a mild attack of asthma, but was able to walk 
slowly. Since the previous study he had had three episodes of influenza with asthma, and was wheezing almost every night. He denied chronic cough or sputum. The lungs showed many high-pitched musical rhonchi, and breath sounds were diminished. Arterial oxygen saturation was $92 \%$.

Case 10.-A woman, aged 28 years, at the age of 27 years had developed asthma, worse in the winter. She was admitted four times in status asthmaticus in 1949 and 1950. No allergic or psychological factors were found. She obtained slight relief from adrenaline. Reassurance was more effective. The first study, on October 13, 1950, was carried out when she was an out-patient and able to walk 10 to 20 yards before being stopped by dyspnoea. Rhonchi were audible throughout the chest. A chest radiograph was normal. A second study (March 27, 1951) was carried out when she was much more dyspnoeic and having frequent attacks of asthma. She had had two severe attacks of bronchitis in the previous three months, which left her with cough, productive of greyish-white sputum. Rhonchi were audible throughout the chest. Arterial oxygen saturation was $88 \%$.

We wish to acknowledge with sincere thanks the interest which Professor J. McMichael has shown in our work and the help which he has given us.

\section{REFERENCES}

Bateman, J. B. (1946). Proc. Mayo Clin., 21, 112.

Bates, D. V., and Christie, R. V. (1950). Clin. Sci., 9, 17.

Birath, G. (1944). Acta med. scand., suppl. 154.

Briscoe, W. A. (1952). Clin. Sci. In the press.

Becklake, M. R., and Rose, T. F. (1951). Ibid., 10, 37.

Fowler, W. S. (1949). J. appl. Physiol., 2, 283.

Gilson, J. C., and Hugh-Jones, P. (1949). Clin. Sci., 7, 185.

Huber, H. L., and Koessler, K. K. (1922). Arch. intern. Med., 30, 689.

Hurtado, A., and Kaltreider, N. L. (1934). J. clin. Invest., 13, 1053.

Fray, W. W., Brooks, W. D. W., and McCann, W. S. (1934). Ibid., 13, 1027.

McMichael, J. (1939). Clin. Sci., 4, 167.

Roelsen, E. (1938). Acta med. scand., 95, 452.

(1939). Ibid., 98, 141 . 